\title{
MODOS E FORMAS: DIMENSÕES FILOSÓFICAS DA CRÍTICA MARXIANA DA ECONOMIA POLÍTICA
}

\author{
Antônio José Lopes Alves* \\ ajla@uol.com.br
}

RESUMO O presente artigo se refere a uma parte integrante do projeto de pesquisa intitulado "A Cientificidade na Obra Marxiana de Maturidade" $e$ pretende explicitar o estatuto categorial, determinativo, de dois dos principais conceitos que integram a crítica marxiana da economia política em sua versão madura: formas de ser e modos de produção. Tomados na linguagem corrente como praticamente sinônimos, as duas noções ganham no corpus cientificofilosófico construído pela reflexão marxiana, cada qual, uma significação bastante precisa. Propomo-nos a esclarecer o conteúdo e a função teóricos cumpridos pelas duas categorias em questão, chamando a atenção para o problema da articulação categorial pensada que, em Marx, deve reproduzir, ou seja, traduzir e transpor o real na cabeça do homem. Procurar-se-á assim delimitar o efetivo sentido dos modos, histórico-sociais concretos, como modalidades de articulação de formas de ser efetivas da sociabilidade. Modos e formas de ser de entes, relações e processos sociais são momentos da determinação categorial da realidade societária. De um lado, tem-se a multiplicidade das efetivas formas de ser de relações, atividades e produtos. De outro lado, é a articulação que preside a vigência das ditas formas como existentes atualmente e parâmetro da sociabilidade como um todo.

Palavras-chave Marxologia, crítica da economia política, categorias, modos, formas.

* Professor de Filosofia do Colégio Técnico da UFMG. Artigo recebido em 31/05/2011 e aprovado em 22/11/2011. 
ABSTRACT This article refers to a part of the research project entitled "The Marxian Scientificity in Maturity Work" and aims to clarify the categorial status, determinative of the two main concepts that are part of the Marxian critique of political economy in its mature version: forms of being and modes of production. Taken in the current language as virtually synonymous, the two concepts gain in scientific and philosophical corpus built by Marxist reflection, each one, a fairly precise meaning. We propose to clarify the theoretical content and function fulfilled by the two categories in question, drawing attention to the problem of articulation categorical thought that, in Marx, to reproduce, that is, translate and transpose the real man's head. Search will thus define the actual meaning of the modes, concrete social-historical, as kinds of articulation to be effective forms of sociability. Ways and forms of being loved, relationships and social processes are moments of categorical determination of corporate reality. On one side, there is a multiplicity of ways to be effective in relationships, activities and products. On the other side, is the joint that presides over the duration of that currently existing ways and parameter of sociality as a whole.

Keywords Marxology, critique of political economy, categories, modes, forms.

O presente artigo se propõe a enfrentar o problema das conexões determinadas entre o modo de produção, o e as formas do ser de entes, relações e processos, a modalidade de existência atual desses elementos dentro dos quadros de uma sociabilidade específica no âmbito da crítica marxiana da economia política em sua fase de maturidade. Esse momento do desenvolvimento da reflexão de Marx acerca do mundo do capital se inaugura com a redação dos Grundrisse, entre os anos de 1857-1858, manuscritos nos quais aparece pela primeira vez a distinção categorial entre trabalho $e$ força de trabalho. A partir dessa delimitação conceitual, Marx poderá então reconfigurar a cientificidade exercitada pelos economistas no sentido de proceder à compreensão teórica do núcleo determinativo da moderna produção social. No interior desse quadro conceitual forma e modo assumem sentido bem preciso e rigoroso, com escopo e direção próprios, passando a indicar níveis de determinação teóricos que expressam por sua vez dimensões ônticas distintas da vida social. As categorias que perfazem um determinado modo de 
produzir a existência social dos indivíduos são entendidas, por um lado, como momentos de uma totalidade efetivamente existente, como formas específicas particulares do ser da interatividade societária. Por outro lado, o próprio modo é um conjunto de relações e processos havidos entre aquelas formas concretas do existente. Assim, o que se observa no pensamento marxiano maduro é uma interelação categorial, na qual modos e formas, preservando sua distinção de nível de determinação ontológica, perfazem como unidade efetiva uma determinada modalidade de existência da produção social. O caráter dessa interação entre os níveis de determinação do existente é o que se explicita a seguir.

No que respeita à cientificidade marxiana, as categorias de uma dada sociabilidade podem muito bem, quanto à sua existência histórica concreta, serem anteriores ao modo de produção em investigação, por exemplo, a troca de mercadorias ou a própria mercadoria em relação à produção capitalista. Permanecem sendo concretamente, mesmo após seu momento genético ter se esgotado ou extinguido. No entanto, assumem feições diversas daquelas vigentes em seu início. Para além das aparências do imediato, não obstante conservando até mesmo sua Erscheinungsform anterior, são transtornadas e transformadas como elos de uma nova forma de interatividade social. Nesse sentido, determinadas formas sociais, e suas figurações, não são unívocas ou imutáveis, mas podem ganhar conteúdos novos uma vez constituindo elementos de uma nova totalidade, a partir de uma articulação categorial particular diferente e inaudita. As categorias nunca podem ser tomadas in abstracto, separadas e isoladas da formação societária a qual integram. O que, de um lado, especifica e delimita a aproximação categorial, porquanto situa a categoria em questão num contexto de relações circunscrito e particularizado. Mas, por outro lado, indica, concomitantemente, a complexidade das relações entre formas do ser e os modos de produção social nos quais uma categoria pode vir a existir concretamente. $\mathrm{O}$ itinerário histórico de uma categoria, conquanto forneça o caminho real por ela percorrido e sua participação na constituição do modo de produção em análise, não encaminha, necessariamente, a decifração de seu sentido como elemento do próprio modo de produção a ser compreendido. Historicamente, as trocas de mercadorias, mediadas por dinheiro, o desenvolvimento do comércio, não apenas é anterior ao capital, mas são reconhecidas como historische Vorraussetzung. Além disso, a forma mercadoria é allgemeine elementarische Form des Produkts, ou seja, a forma de existência própria dos resultados da produção no mundo do capital. Nesse sentido, não somente essa forma é preeminente historicamente, mas o é igualmente no que tange à determinação econômica essencial do modo 
de produção capitalista. Forma de ser dos produtos que se realiza, pela série de metamorfoses que passa no processo de produção e realização do valor, até atingir aquela específica do dinheiro. Dinheiro que existe não somente como mediação do intercâmbio, papel imediato por este assumido na série do desenvolvimento histórico das trocas, mas que é antes o modo de existência universal da riqueza capitalista. Por essa razão, Marx indicará que "Mercadoria e dinheiro são ambos, pressuposições elementares do capital (elementarische Voraussetzungen des Kapitals), no entanto, somente se desenvolvem em capital (entwickeln sich aber erst zum Kapital) em determinadas condições". ${ }^{1}$

As condições nas quais os elementos assumem a forma capital são, antes de tudo, determinadas relações sociais particulares, historicamente engendradas e reproduzidas como nomos da interatividade. Um conjunto de nexos societários no qual o princípio eficiente da atividade produtiva mesma - a capacidade de trabalho (Arbeitsvermögen) - aparece como mercadoria, vindo a ser assimilada como elo da cadeia do processo de valorização.

Nesse contexto, a produção capitalista se entende, precipuamente, como uma totalidade de relações, no quadro da qual se engendra a particularização histórica das categorias da interatividade social. O modo de produção capitalista é, então, uma determinada articulação categorial onde os elementos constantes da atividade produtiva ganham seu caráter específico de momentos do capital. A produção em geral ganha assim um cunho determinativo, como produção em geral de capital e não como uma pretensa forma abstrata e ahistórica da atividade produtiva humana. Como corolário necessário disso, as demais formas constantes da sociabilidade, como aquelas do intercâmbio, por exemplo, assumem uma nova configuração, não obstante possam conservar a sua aparência antediluviana. De esfera determinante, a troca de mercadorias se converte em Moment determinado pela produção do maisvalor, como forma de mediação da realização deste na forma capital/dinheiro. No contexto já definido pela existência preponderante da relação social do capital, a conexão entre dinheiro e circulação, não é mais aquela da introdução histórica deste no intercâmbio simples de mercadorias, sob a figura da moeda, como meio de troca: "Quando falamos do capital e de sua circulação, nos encontramos num estágio de desenvolvimento social no qual a introdução do dinheiro não comparece $\{$ hereinkommt\} como descoberta, etc., ao contrário 
é pressuposição". ${ }^{2} \mathrm{O}$ dinheiro aparece como elemento da produção do maisvalor sob outra modalidade formal. Não é posto, exteriormente, apenas como mero auxiliar da troca de mercadorias ou do excedente em sua forma objetiva e material, mas existe, entre outras coisas, como notação simbólica do que torna as mercadorias trocáveis. A sua função simbólica, por certo, não suprime a determinação de meio de intercâmbio, mas modifica essa última essencialmente. Porquanto seja ele mesmo nada mais que uma mercadoria passando a funcionar como equivalente, posição objetiva do valor no confronto dos valores em sua pluralidade, o dinheiro tem também um valor. Como tal, é ele posto sob as mesmas determinações da produção e da circulação do capital. Essa reconversão do dinheiro em meio de realização de capital tende a determiná-lo unicamente como elemento mediador do movimento do valor valorizado. Nessa direção, redefine-se a preciosidade do dinheiro, de qualidade por-si, ou mesmo atribuída convencional ou politicamente, da moeda torna-se propriedade posta pelo funcionamento daquele no circuito do capital. A própria forma imediata do dinheiro, na objetividade figurada na moeda, tende também a ser transtornada, tornando o seu custo cada vez mais irrelevante. No interior dessa tendência, segundo Marx, “(...) o capital o [o dinheiro] transforma em um momento puramente ideal de sua circulação". ${ }^{3}$ Tal reconfiguração do dinheiro, que afeta inclusive sua figuração imediata, como moeda, não advém somente, e não propriamente, de contingências de natureza técnica ou histórica, mas da determinação da forma da produção. Produção esta que não é tão somente de mercadorias, mas, acima de tudo, de capital. Modo de produzir que enquadra a forma mesma da circulação num contexto onde Zirkulation ohne Zirkulationszeit ist die Tendenz des Kapitals. ${ }^{4}$ A vida do dinheiro, e de sua figuração mais aparente - a moeda - passa a ser determinada pela regra geral da produção de riqueza como capital.

Desse modo, como a produção se destina à criação de mais-valor e a circulação à realização deste como excedente em dinheiro, a mercadoria aparece como forma universal necessária do produto (allgemein notwendige Form des Produkts), é a forma de existência correspondente dos elementos objetivamente participantes do processo de produção capitalista. Esse conjunto compreende tanto os resultados, os valores produzidos no curso do processo de valorização, quanto das condições deste mesmo processo. Por

2 Marx, K. Grundrisse: Ökonomische Manuskripte 1857/1858, In: Marx-Engels Werke, Band 42, Dietz Verlag, Berlin, 1983, p. 571.

3 Idem.

4 Cf. Idem, em especial, pp. 443-444, 572 e 659. 
conseguinte, essa forma social de ser é assumida por aqueles elementos, independentemente das circunstâncias particulares e das características físicas e objetivas das coisas e processos mobilizados na produção. Antes, esses assumem para si, como uma destinação, o papel de mediadores concretos da valorização. Forma social do ser da produção que preside a série de momentos, aparecendo no curso do processo seja efetivamente, como caráter específico da riqueza que determina os produtos, seja idealmente, como posição prévia dos produtos na forma mercantil na contabilização destes como itens do capital a ser reproduzido e valorizado. Esse cunho geral se impõe como norma e se apodera da produção social da riqueza em sua totalidade, não apenas nos ramos que são historicamente contemporâneos do modo de produção capitalista (o caso da grande indústria maquinal), mas igualmente naqueles que lhes são cronologicamente anteriores, mas que continuam a existir; a agricultura, por exemplo. Dessa maneira, à preponderância crescente, no nível da processualidade histórica, das formas categoriais do capital - em especial, da sua forma elementar, a mercadoria - no âmbito da interatividade social, corresponde, no que tange à existência atual do sistema, ao seu funcionamento, à assimilação do caráter mercantil como algo próprio e inerente aos seus constituintes e processos objetivos. Daí pode surgir inclusive a ilusão que considera uma forma histórica um dado inerente aos produtos da atividade como tais.

A mercadoria possui, no modo de produção capitalista, por assim dizer, um duplo modo de exposição (Ausdrucksweise). De um lado, aparece como mercadoria simples, forma elementar imediata do resultado do processo de produção. Nesse contexto, sua determinidade simples exprime abstratamente, de modo isolado e imediato, como dado "natural", a determinação essencial que preside e regula a valorização do valor. Unidade imediata de valor e valor de uso, a forma mercadoria apresenta o conjunto das determinações de existência do capital à maneira de propriedades intrínseca e naturalmente objetivas. A mercadoria aparece como figuração autônoma, modo de existência direta, originada da atividade produtiva. Nesse sentido, "como resultado e produto direto de um quantum determinado de trabalho", tomada como produto do capital (Produkt des Kapitals), diversamente, a mesma forma se apresenta como mediação da realização efetiva da riqueza. Como tal, a mercadoria dada singularmente vale como parte alíquota do produto total, do valor valorizado, do produto existindo como capital e, sendo assim, vale e se afirma na totalidade de momentos que constituem o circuito de realização do mais-valor - aí incluso aquele da circulação - como portador do capital total (Träger des Gesamtkapitals). Modo de existência que se exprime efetivamente na posição 
do preço como expressão do valor das mercadorias. Não se trata da colocação do preço de uma mercadoria imediata e isoladamente dada, mas desta, como momento do produto total do capital, como parte constante do capital como totalidade do produto do processo de valorização, o qual se expressa como plêiade de mercadorias.

O processo de valorização não abole empiricamente a posição do valor de uso particular e concreto dos produtos ou das condições da produção. Nesse sentido, a identidade entre processo de produção e de valorização não significa a anulação da finitude própria e objetivamente discernível dos elementos envolvidos e mobilizados na posição/extração de mais-valor. Ao contrário, o processo de trabalho continua a engendrar uma massa de valores de uso efetivos, a serem consumidos segundo sua especificidade objetiva. No entanto, como processo de valorização, de efetuação de maisvalor, a produção de mercadorias se converte em produção de artigos cuja principal determinação é a de representar (stellen) o capital como um todo. Nesse sentido, a "massa de valores de uso produzida representa \{stellt $\}$ um quantum de trabalho = ao valor contido e consumido no capital (aos quanta de trabalho materializado transmitido ao produto) + aos quanta de trabalho trocado por capital variável, do qual uma parte substitui o valor do capital variável e outra constitui $\{$ bildet $\}$ o mais-valor". ${ }^{5}$ A mercadoria se despe assim de sua aparente simplicidade imediata e se revela forma de existir particular do capital, realização empírico-objetiva da valorização e por este lado é uma determinada forma representativa do curso do próprio processo de produção capitalista. Como forma social concreta e específica de um ente, a mercadoria remete ao modo societário, ao conjunto de relações sociais, no bojo do qual transcorre a interatividade, a produção da vida humana, num contexto histórico particular. Por isso, a forma mercadoria é considerada por Marx como forma elementar da riqueza produzida nos parâmetros do capital. Não somente por seu caráter de efetivação imediata do excedente, a existência mesmo deste plus social da produção como unidade ou entificação discreta, discernível objetivamente, mas, principalmente por seu talhe sintético. A figuração concreta da mercadoria vale assim e dessa maneira se reafirma no curso dos momentos da valorização - da produção dos valores à realização final como capital/dinheiro, figura autônoma do valor valorizado - como síntese objetiva da malha relacional que preside necessariamente a atividade produtiva capitalista. Uma entificação dada, cuja existência, para ser como tal mercadoria,

5 Marx, K. Resultate des unmittelbaren Produktionsprozess, Op.Cit., p. 103. 
precisa afirmar-se como objetividade - física ou não - dos produtos que serão lançados inexoravelmente à circulação e ao mercado, com o fito precípuo de fazer aparecer na ponta final do processo o mais-valor produzido e posto como parte $(T e i l)$ do valor dos produtos. O capital se determina então não como simples meio de produção, mas sendo especificamente a forma do ser adotada ou assumida pelos variados meios de produção, como meios de produção de mais-valor, da riqueza na forma do valor excedente àquele despendido como capital variável (no salário). Marx dessa maneira determina a função social dos meios de produção no mundo do capital: "A função específica, verdadeira, do capital como capital, é, pois, a produção do mais-valor, que, como se apresenta ulteriormente, nada mais é que produção de trabalho excedente, apropriação de trabalho gratuito no processo de produção efetivo, que se apresenta concretamente \{vergegenstandlicht\} como mais-valor". ${ }^{6}$

Por isso, as mercadorias em sua pluralidade integram, então, essencialmente o processo não apenas no que concerne à produção como processo concreto de trabalho, transformando-se de instrumentos e materiais em produtos por meio da intervenção ativa da força de trabalho. Aquelas o fazem igualmente no que tange ao aspecto formal, de caráter unicamente social, concomitante e sequencialmente ao momento da produção em sentido estrito e tomado isoladamente como ponto de partida:

Como mercadoria, o produto do capital deve entrar no processo de troca das mercadorias \{Austauschprozess den Waren\}, e com isso não apenas nas transformações materiais efetivas \{in den wirklichen stoffwechsel), senão igualmente passar por \{durchmachen) cada uma das alterações da forma \{Formverwandlungen\}, o qual apresentamos como metamorfose das mercadorias. Porquanto se trate apenas de alterações formais - a transformação dessas mercadorias em dinheiro e a retransformação deste \{Rückverwandlung em mercadorias - se fazem (bereits) no processo sob o nome de "circulação simples" - a circulação das mercadorias como tal. $^{7}$

A forma mercadoria não remete, então, somente à série de determinações imediatamente atinentes à existência da mercadoria como figuração elementar e abstrata da riqueza, mas aponta para a determinação essencial, à preponderância categorial, da differentia specifica da produção capitalista, como produção do capital por meio, e ato contínuo, da de mercadorias. Não se trata, por conseguinte, da mera criação e venda de mercadorias, e sim da operação processual de valorização, da capitalização, tendo por mediação 
subordinada, ainda que imprescindível, o momento da circulação. De modo que "essas mercadorias são agora igualmente portadoras do capital \{Träger des Kapitals\}; estas são o próprio capital valorizado, emprenhado \{geschwängerte\} com mais-valor". ${ }^{8}$ Com isso, a própria movimentação de mercadorias é engendrada e metrificada pela forma da produção de capital, a qual regula como nomos o conjunto das relações que integram a sociabilidade do capital. A denominada circulação simples tem revelada analiticamente seu caráter de determinação mais essencial. Não se trata mais do mero ir e vir das mercadorias em sua aparente contingência e dependência do mercado, tomado como momento ou nicho em separado e autônomo com relação à produção/valorização. Ao contrário, esse espaço social no qual os produtos perambulam é ele mesmo um desdobramento da forma da produção social do capital, não importando aqui mais o fato de sua existência histórico-empírica ser de muito antecedente a do capital como tal. Como categoria do modo de produção capitalista, o mercado, a existência atual da circulação do capital no decurso da sua realização plena, como valor valorizado a ser expresso em sua forma autônoma e indiferentemente permutável (dinheiro), é um momento necessariamente implicado no processo e por este delimitado.

Essa remissão característica das formas com relação à articulação que perfazem um dado modo de produção pode ser observada com especial clareza quando se considera a forma mercadoria em sua concatenação com a produção do capital enquanto tal. A dúplice determinidade da mercadoria - valor e valor de uso - que aparece já na sua figuração mais aparente, como ente tomado isolado e abstratamente, remete à determinação essencial do próprio processo de trabalho como processo de valorização. Desse modo,

Assim como a mercadoria é a unidade imediata de valor de uso e valor de troca, o processo de produção, o processo de produção de mercadoria, é a unidade imediata do processo de trabalho e do de valorização. Como mercadorias, isto é como unidade imediata de valor de uso e valor de troca, como resultado, como produto, aparecem ao processo \{aus dem prozess herauskommen\}, então como um elemento constituinte dele. ${ }^{9}$

Conexão essa entre a forma da atividade e aquela do produto que determina o conjunto das mediações sociais através das quais o processo de valorização, a produção propriamente dita do capital, chega a seu termo. Unidade de determinações que exige e põe as condições necessárias ulteriores à realização

8 Idem.

9 Marx, K. Resultate des unmittelbaren Produktionsprozess, Op.Cit., p. 11. 
do mais-valor em sua forma autônoma de valor e simultaneamente encaminha o momento das transações mercantis como pressuposição implícita no processo. A circulação não se limita mais, assim, à forma imediata de transação simples, cujo objeto é o multiverso das mercadorias tomadas na sua imediatidade, como entes de valor. No curso da analítica marxiana se ultrapassa esse limiar abstrato e se explicita o momento determinante dos movimentos mercantis. $\mathrm{O}$ circuito de realização do valor, nele incluso o mais-valor, engendrado pelo processo de produção de mercadorias se põe como o movimento em essência que se efetiva como circulação de mercadorias. Trata-se, portanto, do Zirkulationsprozess des Kapitals e não mais apenas das múltiplas operações de trânsito dos resultados do processo imediato de produção in abstracto. $\mathrm{O}$ mais-valor com o qual o valor anteriormente posto nas diversas condições objetivas de produção é fecundado e enriquecido constitui o verdadeiro alvo do processo. Como meta precípua da atividade produtiva, se subsumem como elos determinados os demais elementos e passos da sucessão de momentos que levam à reemergência do valor (plus mais-valor) na forma de dinheiro (como um mais-dinheiro).

O fato de essas formas desempenharem o papel de mediações efetivas da valorização do valor, entretanto, não faz com que as suas figurações sejam de per se capital. A esse respeito, Marx chama a atenção, no mesmo manuscrito em tela, para o duplo equívoco em que incorre o empirismo abstrato da economia política: "Os economistas cometem a mancada \{blunder\} de, por um lado, identificarem essas formas elementares do capital \{Elementarformen des Kapitals $\}$ - mercadoria e dinheiro - como tais ao capital, por outro lado, ao declararem capital o modo de existência do valor de uso \{Gebrauchswertsexistenzweise $\}$ do capital - o meio de trabalho - como tal". ${ }^{10}$ Erro dúplice de atribuir ao capital uma mera existência empírica, de tomar a forma de aparição específica e determinada do capital, como valor de uso incluso e mobilizado no processo de produção/valorização, como o único aspecto do problema. O empirismo abstrato parte da aparência do processo como instância dada, sem interrogar-se pelas determinações que possam operar em níveis menos imediatos. À identificação sem mais de dinheiro e condições de produção a capital, corresponde outra, na qual o capital como tal é concebido como mero conjunto dos elementos objetivos da produção. As formas são manipuladas no limite estrito da sua dação direta e imediata, e, no máximo, segundo as determinidades que podem ser apreendidas nos

10 Marx, K. Resultate des unmittelbaren Produktionsprozess, Op.Cit., p. 8. 
contornos das figuras compreendidas na produção da riqueza como capital. De uma parte, tem-se a naturalização social do capital, ou seja, a fixação do caráter particular histórico de uma relação societária, nos marcos da qual se dá a valorização do valor como meta da produção, como modo de existência pertencente à natureza mesma do ato produtivo, e dos meios e objetos neste movimentado e por este implicado. A forma capital se apresenta, nesse contexto, como uma forma inerente à produção social da vida como tal, independentemente das circunstâncias efetivas nas quais transcorra. De outra parte, em complementaridade, o capital, de forma do ser da riqueza (e das suas variadas condições de produção) num contexto histórico-social dado, é tomado então como mero elemento de produção, igualado ao valor de uso próprio de cada um dos termos que se relacionam na produção. Os meios/ condições são, imediatamente, capital, e este é, igualmente, de modo direto, caráter que vem a inerir aos objetos em sua existência físico-objetiva.

A complexidade específica inerente e imanente à produção como processo de valorização se afirma na medida em que se leva em conta a emergência de determinações particulares que delimitam a mercadoria quando esta se põe como condição da produção. Ultrapassando, como já se notou mais acima, o seu caráter mais imediato, delimitado pelas determinidades abordáveis na mercadoria tomada abstratamente. Assim,

Consideramos agora a figura do capital \{die Gestalt des Kapitals\} no interior \{innerhalb\} do processo imediato de produção, então se tem a mercadoria sob a dupla figura \{Doppelgestalt $\}$ de valor de uso e valor de troca. Mas em ambas as formas, trata-se \{treten\}, além disso, de determinações diferentes, daquelas que se observam naquela da mercadoria simples e autônoma, de determinidades mais desenvolvidas \{weiter entwickelte Bestimmtheiten\}. ${ }^{11}$

Nesse sentido, tomada como condição de produção no bojo do complexo do processo de valorização, a mercadoria, figura simples e elementar da riqueza, se desvela como entificação cujo conjunto determinativo se constitui, por sua vez, de elementos que a tornam forma ela mesma complexa. A univocidade da mercadoria, em que pese a dúplice determinação que está inclusa já na sua simplicidade imediata, é desvelada como aspecto meramente aparente. Por exemplo, o valor de uso, em cuja forma de existência imediata, aparenta ser preenchido por um conteúdo até mesmo simplório, apresenta-se tomado na mercadoria como condição do processo de produção/valorização, uma dupla conotação objetiva. O ser dos meios de produção se determina 
de um lado, como conjunto de matérias ou de objetos a serem moldados na forma de um valor no curso da produção, e, de outro, como instrumentos de produção. Nas palavras de Marx, "Essas são as determinações da forma \{Formbestimmungen\} do valor de uso, advindas da natureza mesma do processo de trabalho, e assim, em referência ao meio de produção, se determina mais fortemente o valor de uso". ${ }^{12}$ Diferentemente do modo como o valor de uso se apresenta subsumido ao valor na imediatidade da forma da mercadoria simples, no tocante ao processo de criação do mais-valor, é ele que emerge como momento predominante por excelência do complexo categorial: "A determinação da forma do valor de uso torna-se aqui o essencial mesmo para o desenvolvimento das relações econômicas, das categorias econômicas" \{Die Formbestimmung des Gebrauchswerts wird hier selbst wesentlich für die Entwicklung des ökonomischen Verhältnisses, der ökonomischen Kategorie $\}.{ }^{13} \mathrm{E}$ isso, frise-se energicamente, não por motivos de natureza extracientífica, num enquadramento moralizante da argumentação ou, em seus antípodas, como derivado de um volteio metodológico repentino. Ao contrário, a mutação do grau de determinação da categoria nos quadros da compreensão teórica da produção ocorre em correspondência com o papel determinativo que o valor de uso passa a desempenhar efetivamente, como elemento da mercadoria, como condição de produção.

A centralidade da determinação da forma do ser do valor de uso no processo de valorização é atinente não apenas às condições objetivas, mas igualmente, e principalmente, ao estatuto categorial da força de trabalho integrada ao capital. Funcionando ou valendo (gelten) como mercadoria, assumindo esta forma, dentro do complexo da produção capitalista, uma capacidade, ou um conjunto delas, tem seu usufruto produtivo trocado por uma parte do capital. Seu vendedor, o indivíduo trabalhador vivo e ativo, desloca formalmente de si um momento de sua existência concreta, tornando-o um elemento alienável por um dado quantum de dinheiro o qual deve corresponder, em tese, ao seu valor expresso na quantidade de valor socialmente produzido necessário à reprodução das suas propriedades orgânicas e intelectuais como força de trabalho. Assimilado e assumido como mercadoria pelo capital, a capacidade do sujeito passa a apresentar-se na figura mercantil como uma parte do valor de uso do próprio capital. Ou seja, uma particularidade individual emerge, porquanto possua agora o caráter social objetivo de condição produtiva, como forma de aparição da relação capital: 
Uma parte do valor de uso, no qual aparece o capital no interior do processo de produção é a própria capacidade de trabalho viva \{lebendige Arbeitsvermögen\}, mas como capacidade de trabalho determinada, correspondente à especificação do valor de uso particular do meio de trabalho e como capacidade de trabalho operante \{sich betätigendes Arbeitsvermögen\}, como força de trabalho exteriorizando-se adequadamente \{sich zweckmassig äussernde Arbeitskraft\}, que opera $\{$ Betatigung macht $\}$ o meio de produção em seus momentos objetivos e converte por meio disso a forma original desses valores de uso na forma nova do produto. Os próprios valores de uso sofrem assim no interior do processo de trabalho, um efetivo processo de transformação \{einen wirklichen Verwandlungsprozess\} de natureza mecânica, física e química. ${ }^{14}$

A determinação da capacidade de trabalho como força objetiva do capital, entretanto, não significa uma fantasmagórica transformação desta em um elemento abstrato, sem particularidade. Conquanto o valor de uso da capacidade de trabalho importe ao capital em seu aspecto mais geral, como posição de mais-valor, a valorização tem necessariamente de transcorrer sob a forma concreta da produção de algum valor de uso. O que implica na exigência da atividade produtiva como processo de objetivação particular da capacidade de trabalho, em seu exercício como força de modificação da forma objetiva dos meios de produção. É importante notar com relação a isso o fato de que se, primeiramente, as condições objetivas e subjetivas aparecem necessariamente determinadas na forma do capital, quando de sua assimilação, num segundo momento, o capital aparece igualmente de modo forçoso como um conjunto de valores de uso em operação pela força de trabalho: “(...) o processo de trabalho inteiro como tal, na interação viva de seus momentos objetivos e subjetivos aparece como a figura global \{Gesamtgestalt\} do valor de uso, isto é, [como] a figura real do capital no processo de produção". ${ }^{15}$ Consequentemente a forma efetiva do capital é aquela na qual o processo de valorização pode ser levado a efeito, na mobilização objetiva do valor de uso dos seus momentos constituintes, em uma operação concreta. O capital passa assim da sua forma dinheiro para aquela mais apropriada à criação de mais-valor, e as condições nele apropriadas passam a existir como capital efetivamente atuante. Nesse contexto, tomam uma figuração "na qual, essas funcionem \{funktionieren\} efetivamente como capital, isto é como meio de criação de valor, de valorização do valor, isto é de sua valorização. Esses meios são, portanto, capital". ${ }^{16}$

14 Marx, K. Resultate des unmittelbaren Produktionsprozess, Op.Cit., p. 12.

15 Idem.

16 Marx, K. Resultate des unmittelbaren Produktionsprozess, Op.Cit., p. 14. 
Por conseguinte, a elaboração teórica marxiana não pode ser entendida como uma argumentação construída em torno de formas conceituais, cuja tessitura resulte numa ordem qualquer de rigidez determinativa. Nesse sentido, as categorias não se definem, nem se acham circunscritas em seu âmbito de validade, por um estatuto unívoco e invariável. As Daseinsformen não podem ser compreendidas sob o mesmo critério com o qual tradicionalmente se opera em epistemologia. E isso, nem em uma acepção formalista, onde as categorias se encontrem delimitadas em seu conteúdo e escopo, e se referiram umas às outras já nesse enquadramento; nem em um contexto dialético-especulativo, no qual, não obstante a admissão da transformação e transmutação categoriais, um determinado conceito permanece sendo o preponderante, em última instância, em termos absolutos. No caso da analítica marxiana, o reconhecimento da concretude finita como o terreno de onde efetivamente a cognição se arranca e ao qual esta deve estar sempre referida, tem como consequência uma reconfiguração da definição da própria noção de determinação. O momento preponderante, übergreifend Moment, é reconhecido pelo procedimento analítico como tal, na dependência irremediável da identificação daquela entre as diversas categorias que, na articulação objetiva da coisa, se mostra como efetivamente determinante e subsumindo as demais. Nesse diapasão, é o complexo enfrentado analiticamente, e não uma eleição metodológica ou conceitual, que irá apontar a natureza e o grau das relações de determinação existentes entre as categorias.

Com relação à determinação precisa das categorias que vigem como formas de ser da sociabilidade, o decisivo é o modo pelo qual estas se integram e se remetem reciprocamente na armação de um dado modo de produção específico. Daí o papel eminente, como já o assinalamos de passagem, conferido por Marx à delimitação da differentia specifica. Componente fundamental da crítica marxiana da economia política, esse momento analítico aponta para a constituição de uma determinação modal de caráter histórico-social, a qual estrema e, em alguns casos, restringe o conteúdo e a vigência categoriais. Assim, “(...) tampouco as mercadorias e o dinheiro são em si e por si capital". O que vale tanto para as coisas quanto para seus possuidores, na medida em que "estes apenas se transformam em capital a partir de determinadas pressuposições \{unter bestimmten Voraussetzungen\}, apenas sob estas mesmas pressuposições \{unter deselben Voraussetzungen\} o é o possuidor de mercadoria e dinheiro em capitalista". ${ }^{17}$ Tanto assim é que, 
a forma dinheiro em sua imediatidade, como dada soma de valor de troca em forma autônoma é definida por Marx, linhas abaixo das citadas, como ersten provisorischen Form do capital. Ou seja, o dinheiro somente é propriamente capital porquanto se engaje, por meio da ação dos seus possuidores, no roteiro seguido pelo processo de valorização; o dinheiro deve tornar-se capital, para tanto dies Geld soll sich verwerten. Nota bene que as formas do ser não se identificam imediata e resumidamente à figuração físico-objetiva, são antes determinadas relações sociais que plasmam características das quais se revestem as condições e produtos da interatividade. Em momento ulterior da argumentação, no mesmo escrito em tela, Marx retoma essa questão, agora no horizonte delimitado pela relação entre processo imediato de trabalho e processo de valorização. Desse modo, chama a atenção para o fato de que o aspecto mais direto da produção, criação de artigos cujas propriedades satisfazem dados carecimentos humanos, obra no sentido de perder-se de vista o que determina a produção como especificamente capitalista:

(...) como o processo de produção do capital é em geral \{überhaupt\} processo de trabalho, o processo de trabalho como tal, o processo de trabalho em todas as formas sociais seria necessariamente processo de trabalho do capital. O capital seria então considerado como coisa que desempenha \{spielt\} um dado papel real \{eine gewisse dingliche rolle , a ela atribuído no processo de produção. É essa mesma lógica que conclui que em sendo o dinheiro ouro, o ouro seria em si e por si dinheiro, em que como trabalho assalariado, todo trabalho é necessariamente assalariado. Provase então a identidade a partir do que é idêntico em todos os diversos processos de produção, separando-o \{festgehalten wird\} de suas diferenças especificas. ${ }^{18}$

Nesse sentido, o capital não é uma coisa, não se identifica às condições objetivas e subjetivas concretas da produção, mas é antes um determinado caráter social assumido por estas, uma forma de comportar-se e de viger socialmente de coisas e indivíduos. Os elementos assim dados werden sollenden Kapitals, devem vir a tornar-se capital. Capital é precisamente uma relação social pela qual o valor se valoriza por meio da produção, um comportamento social no qual a atividade tem por norma e telos o engendramento de um excedente em valor: "A produção de mais-valor - a qual contém a conservação do valor original anterior - aparece então como o fim determinante \{bestimmende Zweck\}, o interesse motor e resultado acabado \{schliessliche Resultat\} do processo de produção capitalista, como por meio do qual o valor original se transforma em capital". ${ }^{19} \mathrm{O}$ modo de produção é uma particular determinação 
modal das categorias. É uma articulação particular na qual as categorias assumem determinadas características e matizes específicos, por meio dos quais se dá a concatenação das mesmas num todo de relações.

\section{Referências bibliográficas}

ALTHUSSER, L. - Pour Marx, Paris: Maspero, 1965.

BIDET, J. - Explication et reconstruction du Capital, Paris : PUF, 2004.

CHASIN, J. - Marx. Estatuto Ontológico e Resolução Metodológica, São Paulo: Boitempo Editorial, 2009.

LUKÁCS, G. - Die ontologischen Grundprinzipien von Marx, In: Zur Ontologie des gesellschftlichen Seins, Darmstadt und Neuwied: Hermann Luchterhand Verlag, 1984. MARX, K. - Resultate des unmittelbaren Produktionsprozess, In: Das Kapital. I. Buch. Der Produktionsprozess des Kapitals. VI. Kapitel, Archiv sozialistischer Literatur 17. Frankfurt: Verlag Neue Kritik, 1970.

- Das Kapital, erster Buch - Kritik der politischen Ökonomie, In: MARX / ENGELS Werke, Band 23. Berlin: Dietz Verlag, 1998.

- Grundrisse der Kritik der politischen Ökonomie, In: MARX / ENGELS Werke, 42. Berlin: Dietz Verlag, 1983.

ROSDOLSKY, R. - Gênese e estrutura de O Capital de Karl Marx, Rio de Janeiro: Contraponto/Eduerj, 2002. 